\title{
ANALISIS KINERJA RUAS JALAN TERHADAP PENGARUH HAMBATAN SAMPING PADA JALAN A.M. SANGAJI GONOF KM.12 KOTA SORONG
}

\author{
Faried Desembardi ${ }^{1)}$, Agus Sukrisman ${ }^{2)}$, Harfli Ulayanto ${ }^{3)}$ Hendrik Pristianto $^{4)}$ \\ 1),2),3),4) Program Studi Teknik Sipil Universitas Muhammadiyah Sorong \\ Jl Pendidikan No 27 Kota Sorong \\ Email: faried1964soq@gmail.com
}

\begin{abstract}
Abstrak
Tingginya nilai hambatan samping pada suatu ruas jalan akan menyebabkan penurunan pada kinerja jalan. Tujuan dari penelitian ini adalah untuk menganalisis faktor-faktor yang mempengaruhi penurunan kinerja lalu-lintas pada beberapa kondisi hambatan samping. Penelitian yang dilakukan meliputi survei mengenai volume lalu-lintas, hambatan samping, dan kecepatan kendaraan. Penelitian dilakukan selama 6 hari, pelaksanaan survei dilaksanakan pada waktu-waktu sibuk. Lokasi penelitian di ruas jalan A.M. Sangaji Gonof Km.12, panjang segmen lokasi penelitian 200 meter. Dari hasil survei didapat data yang selanjutnya akan dihitung menggunakan pedoman Manual Kapasitas Jalan Indonesia 1997 untuk Jalan Perkotaan.Dari data survei dan kemudian diolah menggunakan pedoman MKJI 1997 didapat arus lalu-lintas tertinggi pada hari rabu sebesar 756,3 Smp/Jam, kecepatan kendaraan rata-rata 32,84 Km/Jam, kepadatan lalu-lintas (D) 23,03 Smp/Jam, bobot hambatan samping sebesar 333 dengan kelas hambatan samping sedang/medium, kapasitas ruas jalan (C) sebesar $1654 \mathrm{Smp} / \mathrm{Jam}$, derajat kejenuhan (DS) sebesar 0,46 dan tingkat pelayanan jalan (Los) $\mathrm{C}$ yaitu kecepatan arus masih stabil, kecepatan dan pergerakan lebih ditentukan oleh volume yang tinggi.
\end{abstract}

Kata Kunci : Hambatan Samping, Jalan Perkotaan, MKJI 1997

\section{PENDAHULUAN}

\section{Latar Belakang}

Kota Sorong merupakan salah satu Kotamadya di Provinsi Papua Barat dengan tingkat perkembangan ekonomi dan infrastruktur yang cukup pesat, kota sorong memiliki luas wilayah $1,105 \mathrm{~km}^{2}$ dengan perkembangan penduduk pada tahun 2016 mencapai 382.101 jiwa apabila dibandingkan pada tahun 2015 hanya mencapai 374,000 jiwa. Itu berarti jumlah kependudukan di kota sorong naik $10 \%$.

Dalam perkembangannya, peningkatan jumlah penduduk di Kota Sorong setiap tahun mengalami peningkatan, otomatis tingkat kenaikan volume kendaraan pun meningkat, munculnya masalah kemacetan lalu lintas. Kemacetan lalu lintas disebabkan oleh ketidakseimbangan antara peningkatan kepemilikan kendaraan dan pertumbuhan prasarana jalan yang tersedia, serta kapasitas efektif ruas jalan yang ada lebih kecil dari kapasitas jalan yang direncanakan akibat adanya hambatan ditepi jalan. Hambatan samping yang sering terjadi di lokasi studi adalah pejalan kaki, kendaraan berhenti, kendaraan masuk/keluar jalan sisi jalan, dan kendaraan lambat.

Pengaruh hambatan samping terjadi pada sekitar ruas jalan A.M. Sangaji Gonof Km.12. Kota Sorong Pada jamjam puncak diruas segmen jalan tersebut terlihat beberapa aktivitas 
hambatan samping. Sehingga dapat mempengaruhi kinerja pelayanan jalan antara lain dapat menyebabkan terjadinya penurunan kecepatan kendaraan lalu menimbulkan masalah kemacetan.

\section{Rumusan Masalah}

1. Bagaimana pengaruh hambatan samping, terhadap kapasitas ruas jalan, yang dapat mempengaruhi nilai derajat kejenuhan di ruas jalan A.M. Sangaji Gonof Km.12 Kota Sorong?

2. Bagaimana perbandingan kinerja ruas jalan A.M. Sangaji Gonof Km.12 Kota Sorong, pada kondisi saat ini/existing dengan kondisi tanpa pejalan kaki/penyeberang jalan dan kendaraan parkir/berhenti?

3. Bagaimana pengaruh hubungan antara nilai derajat kejenuhan terhadap tingkat pelayanan jalan, yang diakibatkan aktivitas hambatan samping di ruas jalan A.M. Sangaji Gonof Km12 Kota Sorong?

\section{Tujuan dan manfaat}

1. Mengetahui pengaruh dari hambatan samping, terhadap kapasitas ruas jalan yang akan berimbas pada nilai derajat kejenuhan yang merupakan indikator dari kinerja ruas jalan A.M. Sangaji Gonof Km.12.

2. Mengetahui tingkat kinerja ruas jalan A.M. Sangaji Gonof Km.12 pada kondisi saat ini/existing dengan kondisi tanpa pejalan kaki/penyeberang jalan dan kendaraan parkir/berhenti.

3. Mengetahui nilai derajat kejenuhan yang mempengaruhi tingkat pelayanan jalan di ruas jalan A.M. Sangaji Gonof Km.12.

\section{METODOLOGI PENELITIAN Lokasi Penelitian}

Adapun gambar lokasi dapat dilihat pada gambar dibawah ini.

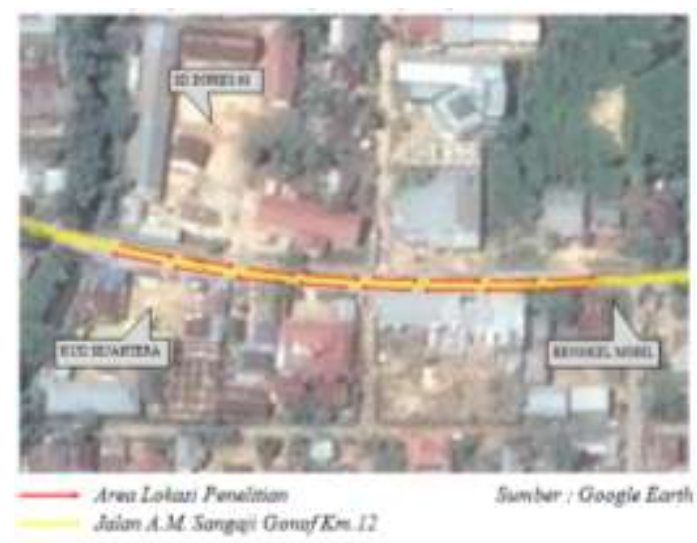

Gambar 1. Lokasi Penelitian

Penelitian ini secara umum di laksanakan di kota Sorong, dengan mengambil lokasi penelitian di Ruas Jl. A.M. Sangaji Gonof Km.12 Kelurahan Klasaman Distrik Sorong Timur.

\section{Metode dan Teknik Pengambilan Data}

Tahap pengumpulan data memegang peran penting dalam keberhasilan penelitian karena tahap analisa dan pengolahan data tergantung pada tahap pengumpulan data. Data yang diperlukan dalam penelitian ini berupa data primer dan skunder. Data primer diperoleh dari survei dilapangan dan data skunder diperoleh dari instansiinstansi yang terkait.

\section{Data Primer}

Data primer merupakan data yang diperoleh dari pengamatan langsung dilapangan meliputi Geometrik Jalan, Kecepatan Lalu-lintas, Volume Lalulintas, dan Hambatan Samping. Lokasi pengamatan akan dilakukan di J1. A.M Sangaji Gonof Km.12 Kota Sorong.

1) Data Geometrik Jalan.

Data geometrik jalan yang diambil antara lain adalah sistem arus lalu lintas, lebar jalan, lebar bahu, lebar per-lajur dan panjang ruas jalan yang di tinjau. 
2) Data Kecepatan Lalu lintas.

Pengukuran data kecepatan dilakukan bersamaan dengan pengambilan data volume lalulintas, diambil data kecepatan kendaraan ringan (LV) 10 sampel, sepeda motor (MC) 10 sampel, dan kendaraan berat 5 sampel.

3) Data Volume Lalu - Lintas

Jenis kendaraan yang di survei menurut MKJI 1997 adalah sepeda motor (MC), kendaraan ringan $(\mathrm{LV})$, kendaraan berat (HV) dan kendaraan tak bermotor (UM). Namun untuk keperluan perhitungan kendaraan bermotor dimasukan ke data hambatan samping.

4) Data Hambatan Samping

Jenis hambatan samping yang akan di survei menurut MKJI 1997, meliputi pejalan kaki/penyeberang jalan (PK), kendaraan berhenti/parkir (KP), kendaraan keluar masuk samping jalan (KM), pedagang kaki lima (PKL) dan keadaan lambat (KL).

\section{Data Skunder}

Data skunder adalah data yang diperoleh dari instansi terkait atau dari sumber lainnya, pengumpulan data Skunder didapat dari :

1) Studi Literatur didapat dari penelitian terdahulu yang berkaitan dengan penelitian yang akan dilakukan.

2) Jumlah Penduduk Kota Sorong didapat dari Badan Pusat Statistik (BPS).

3) Pedoman Manual Kapasitas Jalan Indonesia (MKJI) 1997.

\section{Waktu Penelitian dan Peralatan Penelitian}

Waktu Penelitian

Pelaksanaan survey dilakukan selama enam hari di mulai dari hari senin sampai hari sabtu. Survei pengumpulan data lalu lintas di lakukan pada jam sibuk antara lain : pagi pada pukul 09:30 s/d 10:30 wit, siang pada pukul 11:30 s/d 12:30 wit serta sore pada pukul 16:00 s/d 17:00 wit.

Peralatan penelitian, peralatan yang digunakan untuk melakukan penelitian ini meliputi :

a. Alat tulis yang berfungsi untuk mencatat semua hasil penelitian.

b. Pencatat waktu (Stop Watch) untuk mengukur periode pengamatan kendaraan.

c. Meteran rol 50 meter di gunakan untuk mengukur panjangnya jalan yang di teliti kemudian membagi menjadi per zona.

d. Petugas surveyor, sebagai tenaga pengamatan dan pencatat kebutuhan data primer.

e. Jam tangan sebagai petunjuk waktu selama pelaksanaan survei.

f. komputer untuk kompilasi dan analisa data.

\section{Metode Pengolahan Data}

Setelah data diperoleh dilapangan selnjutnya dilakukan pengolahan data berdasarkan rumus - rumus yang ada, dari data tersebut nanti akan diperoleh hasil untuk melihat tingkat kinerja jalan yang diamati seperti tujuan dari penelitian ini untuk melihat sejauh mana pengaruh hambatan samping terhadap kinerja ruas jalan.

\section{Kecepatan Arus Bebas}

Data yang diperoleh dilapangan selanjutnya dianalisis dengan masukan faktor - faktor penyesuaian yan dibutuhkan untuk mendapatkan nilai kecepatan arus bebas sesuai dengan pedoman MKJI (1997).

\section{Kecepatan Kendaraan}

Dari data kecepatan dilapangan digunakan interval waktu 15 menit untuk kendaraan ringan dan sepeda motor diambil sebanyak 10 sampel, sedangkan untuk kendaraan berat diambil 5 sampel. Kemudian data tersebut direkapitulasi per jam. Data 
tersebut dijadikan kedalam satuan meter per detik (m/detik) dari hasil bagi antara jarak ruas pengamatan dan waktu melintasi ruas, lalu dari satuan meter per detik (m/detik) diubah ke dalam satuan kilometer per jam ( $\mathrm{km} / \mathrm{jam})$ mengalikan dengan jumlah detik dalam satu jam dan dibagi dengan jarak seribu meter (satu kilometer dikonversi ke meter).

\section{Volume Lalu-Lintas}

Data volume lalu-lintas di catat dengan interval waktu 15 menit di lapangan, di jumlahkan ke dalam interval waktu 1 jam untuk keperluan perhitungan menurut jenis kendaraannya. Berdasarkan jumlah kendaraan dengan masing-masing jenisnya, di kalikan dengan angka ekivalensi mobil penumpang (EMP) untuk di ubah ke dalam satuan mobil penumpang (SMP).

\section{Kapasitas Jalan}

Kapasitas pada jalan A.M. Sangaji Gonof Km.12 ditentukan menurut daerah ruas atau arah jalan masingmasing. Perhitungan pada tiap-tiap ruas jalan dengan memasukan faktor-faktor penyesuaian yang di butuhkan berdasarkan pedoman MKJI (1997), untuk jalan tak-terbagi faktor penyesuaian kapasitas untuk pemisah arah $\left(\mathrm{FC}_{\mathrm{SP}}\right)$ tidak dapat di gunakan, maka nilai 1 memasukan pada perhitungan. Lebar jalur yang di gunakan adalah penggunaan lebar jalur yang dapat di lalui kendaraan setelah adanya pengurangan lebar jalur akibat adanya hambatan samping jalan.

\section{Metode Analisa Data}

Setelah di hitung volume lalu-lintas dan di bandingkan dengan nilai kapasitas jalan maka di peroleh nilai derajat kejenuhan (DS), derajat kejenuhan di gunakan sebagai faktor utama dalam penentuan tingkat kinerja jalan dan menenjukan apakah jalan tersebut mempunyai masalah kapasitas atau tidak, nilai derajat kejenuhan tidak boleh melebihi 0,75 (syarat MKJI, 1997). Setelah di dapat nilai derajat kejenuhan selanjutnya akan di lihat pengaruh hambatan samping terhadap kinerja jalan dengan melakukan beberapa skenario penghilangan hambatan samping sehingga di dapat perbandingan analisis dari setiap kondisi jalan terhadap kapasitas dan derajat kejenuhan yang kemudian menjadi tolak ukur dalam memperbaiki kinerja jalan terutama yang di sebabkan oleh hambatan samping.

\section{Kinerja Jalan}

Kinerja jalan di tentukan setelah perhitungan kecepatan rata-rata kendaraan, volume lalu-lintas pada jam sibuk dan kapasitas jalan. Tingkat kinerja jalan dapat di lihat dari nilai kecepatan dan derajat kejenuhan, apabila nilai derajat kejenuhan melebihi 0,75 (syarat MKJI) maka ruas jalan tersebut memiliki tingkat kinerja jalan yang rendah serta menunjukan segmen jalan tersebut mempunyai masalah kapasitas yang dapat menyebabkan kemacetan dan sebaliknya apabila nilai derajat kejenuhan lebih rendah atau sama dengan 0,75 maka kinerja segmen jalan tersebut masih baik dan untuk nilai kecepatan tempuh rata-rata kendaraan ringan yang baik pada jalan A.M.Sangaji Gonof Km.12

\section{Hambatan Samping}

Untuk mengetahui pengaruh masingmasing hambatan samping terhadap kecepatan dan derajat kejenuhan sebagai indikator dari kinerja jalan yang terdapat pada ruas jalan A.M. Sangaji Gonof Km.12 Kota Sorong saat jam puncak maka di buat skenario sebagai berikut :
1) Kondisi
tanpa pejalan
kaki/penyeberang jalan (NO PK)
$\rightarrow($ Skenario 1). 
2) Kondisi tanpa kendaraan parkir/berhenti (NO KP) $\rightarrow$ (Skenario 2).

3) Kondisi tanpa pejalan kaki/penyeberang jalan kendaraan parkir/berhenti $(\mathrm{NO} \mathrm{PK}+\mathrm{KP}) \rightarrow$ (Skenario 3).

\section{ANALISA DAN PEMBAHASAN Kondisi Geometrik}

Dari data kondisi umum ruas Jalan A.M. Sangaji Gonof Km.12, didapat data geometrik jalan sebagai berikut :

a. Sistem arus lalu-lintas : 2/2 UD : 2 Lajur, 2 Arah (2/2 UD)

b. Lebar badan jalan : 5,2 Meter : 5,20 Meter.

c. Lebar Per-Lajur : 2.6 Meter : 2,6 Meter.

d. Lebar bahu jalan kanan : 1,2 Meter : 1,20 Meter.

e. Lebar bahu jalan kiri : 1,5 Meter : 1,50 Meter.

f. Panjang segmen jalan : 200 Meter : 200 Meter

\section{Kelas Ukuran Kota}

Berdasarkan data kependudukan yang didapat dari Badan Pusat Statistik (BPS) Kota Sorong, jumlah penduduk kota Sorong dalam angka 2016 mencapai 225,588 jiwa dengan presentase laju pertumbuhan penduduk $3,10 \%$. Data jumlah penduduk pada setiap distrik kota sorong dapat dilihat pada tabel 1 dibawah ini.

Tabel 1. Data Jumlah Penduduk Kota

\begin{tabular}{|c|c|c|}
\hline \multicolumn{3}{|c|}{ Sorong } \\
\hline No & Distrik & Jumlah Penduduk (Ribu) \\
\hline 1 & Sorong & 31,936 \\
\hline 2 & Sorong Barat & 37,730 \\
\hline 3 & Sorong Kepulauan & 9,899 \\
\hline 4 & Sorong Timur & 42,111 \\
\hline 5 & Sorong Utara & 53,071 \\
\hline 6 & Sorong Manoi & 50,841 \\
\hline & Total & 225,588 \\
\hline
\end{tabular}

Berdasarkan data jumlah penduduk kota Sorong diatas, maka didapat kelas ukuran kota (CS) untuk kota sorong, menurut pedoman MKJI, 1997 untuk kelas ukuran kota (CS). Jumlah penduduk suatu kota dibawah satu juta jiwa dikategorikan kelas ukuran kota sangat kecil. Itu berarti kota sorong termasuk kategori kelas ukuran kota sangat kecil dengan penduduk hanya berjumlah 225,588 (Ribu) jiwa.

\section{Analisa Volume Lalu-Lintas}

Nilai Volume lalu-lintas (Q) adalah jumlah kendaraan yang melewati suatu titik pengamatan dalam interval waktu 15 menit, kemudian diolah menjadi volume lalu-lintas dalam interval waktu satu jam kemudian diekivalensikan ke dalam satuan mobil penumpang (SMP), yaitu dengan cara mengalikan jumlah tiap-tiap jenis kendaraan dengan angka ekivalensi dari masing-masing jenis kendaraan (EMP) yang telah dijelaskan pada Bab II Tabel 2.6 untuk jalan tak terbagi (2/2 UD). Nilai EMP untuk MC adalah 0,4 LV adalah 1,0 dan HV 1,3. Dalam penulisan ini digunakan data lalu lintas-tertinggi, berikut adalah hasil dari rekapitulasi nilai total $\mathrm{kend} / \mathrm{jam}$ dan nilai total Smp/Jam volume lalu-lintas (Q) Pada titik Pengamatan A. Berdasarkan hasil survei pada jam puncak pada hari Rabu, 14/12/2016 dapat dilihat pada tabel 2 dibawah ini.

Tabel 2. Rekapitulasi Volume Lalu Lintas di Titik A Pada Hari Rabu

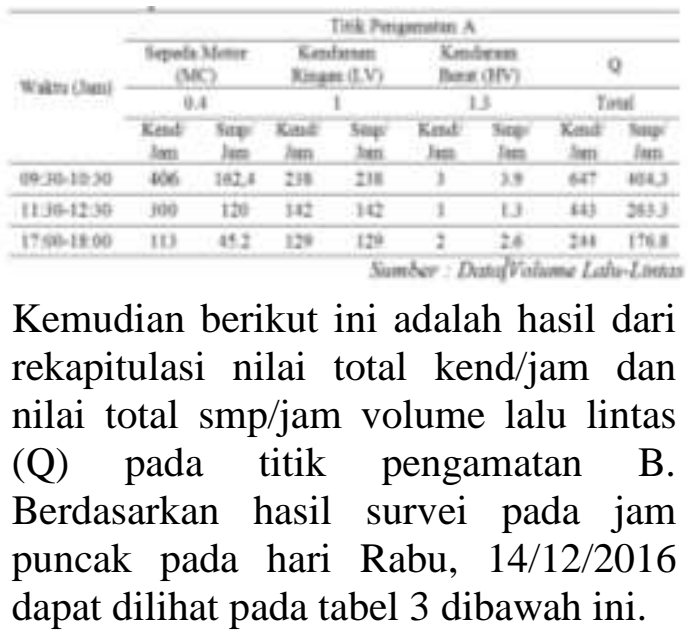


Tabel 3. Rekapitulasi Volume Lalu Lintas di Titik B pada Hari Rabu

\begin{tabular}{|c|c|c|c|c|c|c|c|c|}
\hline \multirow{4}{*}{ Walle (Jim) } & \multicolumn{8}{|c|}{ Tea Progamaian B } \\
\hline & \multicolumn{2}{|c|}{$\begin{array}{l}\text { Sepela Mtonot } \\
\text { (Ax) }\end{array}$} & \multicolumn{2}{|c|}{$\begin{array}{l}\text { Kendaraai } \\
\text { Hityan(1V) }\end{array}$} & \multicolumn{2}{|c|}{$\begin{array}{l}\text { Kendiraul } \\
\text { Betal (t) }\end{array}$} & \multicolumn{2}{|c|}{ Q } \\
\hline & \multicolumn{2}{|c|}{0.4} & \multicolumn{2}{|c|}{1} & \multicolumn{2}{|c|}{13} & \multicolumn{2}{|c|}{ Tat } \\
\hline & $\begin{array}{l}\text { Kenal } \\
\text { Jae }\end{array}$ & $\begin{array}{l}\text { Selp } \\
\text { Jam }\end{array}$ & $\begin{array}{l}\text { Kesal } \\
\text { Jain }\end{array}$ & $\begin{array}{l}\text { Sen } \\
\text { lati }\end{array}$ & $\begin{array}{l}\text { Kesd } \\
\text { Jam }\end{array}$ & Senp & $\begin{array}{l}\text { Keal } \\
\text { Sali }\end{array}$ & $\begin{array}{l}\text { Sep } \\
\text { Jan }\end{array}$ \\
\hline (09.30.10-30 & 372 & 1404 & im & 196 & 4 & 5.2 & 574 & 352 \\
\hline $11.30-12 \cdot 30$ & 236 & 244 & 134 & 134 & 3 & 19 & 373 & 2123 \\
\hline $1700-31000$ & 115 & 46 & 114 & 115 & 3 & 3.9 & 233 & 16.8 \\
\hline
\end{tabular}

Dari kedua data diatas dijumlahkan kembali untuk mengetahui total keseluruhan dari nilai total kend/jam dan nilai total smp/jam. Nilai total keseluruhan kend/jam dan nilai total smp/jam dapat dilihat pada tabel 4 dibawah ini.

Tabel 4. Total Volume Lalu Lintas di Titik A dan B pada Hari Rabu

\begin{tabular}{|c|c|c|c|c|c|}
\hline \multicolumn{6}{|c|}{ Tisik Pengamatan $A+B$} \\
\hline \multirow{2}{*}{$\begin{array}{c}\text { Waktu } \\
\text { (Pervam) }\end{array}$} & \multicolumn{3}{|c|}{ Kend/lam } & \multirow{2}{*}{$\begin{array}{c}\text { Total } \\
\text { Kend / Jan }\end{array}$} & \multirow{2}{*}{$\frac{\text { Toul }}{\text { Senp / Ian }}$} \\
\hline & MC & LV & EN & & \\
\hline $09.30 \cdot 10: 30$ & 778 & 436 & 7 & 1221 & 756,3 \\
\hline $11: 30-12: 30$ & 536 & 276 & 4 & 816 & $495 \mathrm{f}$ \\
\hline $17.00-18 \times 00$ & 228 & 244 & 5 & 477 & 34.7 \\
\hline
\end{tabular}

Kemudian hasil dari nilai total $\mathrm{kend} / \mathrm{jam}$ dan nilai total smp/jam diatas direkapitulasi kembali, untuk melihat nilai tertinggi dari total jumlah volume lalu-lintas (Q) ketika pagi hari, siang hari dan sore hari. Berikut ini adalah grafik hasil rekapitulasi nilai total $\mathrm{kend} / \mathrm{jam}$ dan nilai total smp/jam, berdasarkan data hari Rabu, 14/12/2016 pada tabel 3 diatas

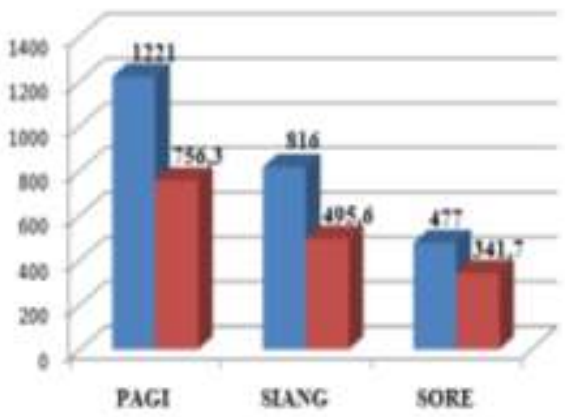

nkend/iam a smpliam

Gambar 2. Grafik Nilai Total Volume Lalu Lintas Hari Rabu

\section{Kecepatan Kendaraan}

Dalam menghitung kecepatan rata-rata kendaraan disuatu segmen jalan, digunakan kecepatan tempuh sebagai ukuran utama kinerja segmen jalan karena mudah dimengerti dan diukur. Untuk itu berdasarkan MKJI,1997 digunakan persamaan 5 diatas

Berikut ini adalah rekapitulasi dari data kecepatan kendaraan pada hari rabu, dapat dilihat pada tabel 5 dibawah ini.

Tabel 5. Rekapitulasi Data Kecepatan pada Hari Rabu

\begin{tabular}{|c|c|c|c|c|c|c|c|c|c|c|c|c|c|}
\hline \multirow{5}{*}{ Siarin } & \multicolumn{12}{|c|}{ 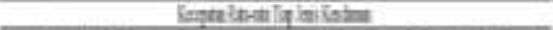 } & \\
\hline & \multicolumn{5}{|c|}{ Gealiken 5} & \multicolumn{4}{|c|}{ Intinn bealin } & & \multicolumn{2}{|c|}{ isiming } & mas \\
\hline & & ind & & an & iefe: & & Ini & Tat & iegta & & in & Ten repde & \\
\hline & WEI & Ifar & & खर्का & Tama & a. & Iapt & lest & Iotan & Wat & lapt 1 & lext laty & \\
\hline & & I & & \$? & (18) & & D & की & (nth & & ij & No & \\
\hline & I & : & & 引 & 193 & E & 2 & 1 & 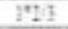 & E & : & In: & \\
\hline 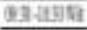 & 鄯 & 11 & & It & 396 & ㄴㅛㅛ & III & Entil & It & 㖣 & II & 进 & IM \\
\hline 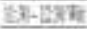 & 政 & I & & 폰 & हैा & 표 & 7 & 27 & 표를 & Fit & IE & Iㅛ & $\$ 5$ \\
\hline 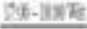 & 30 & 18 & & 2 & 8月 & 造 & in & D & \#i= & Wa & D & Est & F5. \\
\hline
\end{tabular}

\section{Analisa Kepadatan Lalu-Lintas}

Kepadatan lalu-lintas dapat diketahui dengan membagi nilai volume lalulintas dengan nilai kecepatan kendaraan, digunakan persamaan 8 .

Berikut ini adalah analisa perhitungan dari kepadatan lalu-lintas pada hari rabu, dapat dilihat pada tabel 6 dibawah ini.

Tabel 6. Analisa Data Kepadatan Lalu Lintas pada Hari Rabu

\begin{tabular}{|c|c|c|c|c|}
\hline No. & Fals & $V(\bar{K} m \operatorname{lan})$ & Q(Smp las) & D (Seplan) \\
\hline 1 & es $30-10=0$ & 32.4 & 7863 & 2303 \\
\hline 2 & $1150-12 \div 0$ & 935 & 4056 & 124 \\
\hline 3 & $1700-11 \% 00$ & 6724 & 341.7 & 123 \\
\hline
\end{tabular}

\section{Analisa Hambatan Samping}

Dalam menentukan hambatan samping perlu diketahui frekwensi bobot kejadian. Untuk mendapatkan nilai frekwensi berbobot kejadian maka tiap tipe kejadian hambatan samping harus dikalikan dengan faktor bobotnya.

Berikut ini adalah hasil analisa perhitungan dari hambatan samping pada titik pengamatan $\mathrm{A}, \mathrm{B}$, dan $\mathrm{C}$ 
pada hari rabu dapat dilihat pada tabel 7 dibawah ini.

Tabel 7. Analisa Data Hambatan Samping pada Hari Rabu

Rekapitalhei Dasa Hambuan Simping Pada Titoik $\mathrm{A}+\mathrm{B}+\mathrm{C}$

\begin{tabular}{|c|c|c|c|c|c|c|c|c|c|c|}
\hline \multirow{3}{*}{ Waktu (Jam) } & \multirow{2}{*}{\multicolumn{4}{|c|}{ Hambatan Samping }} & \multicolumn{4}{|c|}{ Bobot } & \multirow{3}{*}{$\begin{array}{l}\text { Total } \\
\text { Bobat }\end{array}$} & \multirow{3}{*}{$\begin{array}{l}\text { Kelas } \\
\text { Himbatat } \\
\text { Sumping }\end{array}$} \\
\hline & & & & & (DK) & (KI') & (KM) & (KL) & & \\
\hline & (PK) & (KB) & (KM) & (KL) & es & 1 & 0.7 & 04 & & \\
\hline $69-30-10-30$ & 165 & 151 & 137 & 9 & 825 & 151 & 959 & 36 & 333 & M \\
\hline $1130-12: 30$ & 102 & 75 & 139 & 5 & 51 & 75 . & 973 & 2 & 2253 & L \\
\hline $17.00-18: 00$ & 88 & 52 & 132 & 4 & 44 & 52 & 92.4 & 16 & 190 & L \\
\hline
\end{tabular}

Dari hasil perhitungan hambatan samping yang tertera pada tabel 49 diatas diketahui total bobot hambatan samping suatu segmen pada pukul 09:30 wit - 10:30 wit didapat total bobot 333 berdasarkan tabel 2.5 didapat kelas hambatan samping $\left(\mathrm{SF}_{\mathrm{C}}\right)$ sedang/medium. Kemudian pada pukul 11:30 wit - 12:30 wit didapat total bobot 225,3 dengan kelas hambatan samping $\left(\mathrm{SF}_{\mathrm{C}}\right)$ rendah/low dan pada pukul 17:00 wit - 18:00 wit didapat total bobot 190 dengan kelas hambatan samping $\left(\mathrm{SF}_{\mathrm{C}}\right)$ rendah/low.

\section{Analisa Kecepatan Arus Bebas (FV)}

Kecepatan arus bebas kendaran menurut MKJI, 1997 dapat dihitung dengan mengacu pada persamaan 7 diatas.

\section{Penentuan Faktor Penyesuaian}

1. Kecepatan arus bebas dasar $\left(\mathrm{FV}_{\mathrm{O}}\right)$. Bedasarkan jenis sistem arus lalulintas 2/2 UD maka kecepatan arus bebas dasar adalah sebagai berikut Kendaraan ringan $(\mathrm{LV})=44 \mathrm{Km} / \mathrm{Jam}$

Kendaraan berat $(\mathrm{HV})=40 \mathrm{Km} / \mathrm{Jam}$

Sepeda motor $(\mathrm{MC}) \quad=40 \mathrm{Km} / \mathrm{Jam}$

2. Penyesuaian lebar jalur lalu-lintas efektif $\left(\mathrm{FV}_{\mathrm{W}}\right)$.

Untuk jalan dua lajur tak bermedian faktor penyesuaian adalah lebar jalan total $=5,20$ meter dengan faktor penyesuaian $-6,25 \mathrm{Km} / \mathrm{Jam}$ berdasarkan interpolasi linier

3. Faktor penyesuaian kondisi hambatan samping $\left(\mathrm{FFV}_{\mathrm{SF}}\right)$.
Berdasarkan jenis jalan, dua lajur tak bermedian dengan hambatan samping sedang/medium berdasarkan data hambatan samping tertinggi, serta lebar bahu efektif rata-rata jalan 1,5 meter maka diperoleh faktor penyesuaian sebesar 0,96.

4. Faktor penyesuaian ukuran kota $\left(\mathrm{FFV}_{\mathrm{CS}}\right)$

Berdasarkan data yang didapat dari kantor Badan Pusat Statistik Kota Sorong diketahui jumlah penduduk kota sorong dalam angka 2016 mencapai 225,588 ribu jiwa $(<1$ juta penduduk ), digunakan faktor penyesuaian sebesar 0,90

\section{Perhitungan Kecepatan Arus Bebas} $\mathrm{FFV}=\left(\mathrm{FV}_{\mathrm{O}}+\mathrm{FV}_{\mathrm{W}}\right) \times \mathrm{FFV}_{\mathrm{SF}} \times \mathrm{FFV}_{\mathrm{CS}}$

1. Untuk jenis kendaraan ringan (LV)

$$
\begin{aligned}
\mathrm{FV} & =(44+-6,25) \times 0,96 \times 0,90 \\
& =32,61 \mathrm{Km} / \mathrm{Jam}
\end{aligned}
$$

2. Untuk jenis kendaraan berat (HV) $\mathrm{FV}=(40+-6,25) \times 0,96 \times 0,90=$ 29,16 $=29,16 \mathrm{Km} / \mathrm{Jam}$

3. Untuk jenis sepeda motor (MC) $\mathrm{FV}=(40+-6,25) \times 0,96 \times 0,90=$ 29,16

$$
=29,16 \mathrm{Km} / \mathrm{Jam}
$$

\section{Analisa Kapasitas Ruas Jalan (C)}

Kapasitas ruas jalan dapat dihitung dengan menggunakan persamaan diatas.

\section{Kapasitas Dasar $\left(\mathbf{C}_{\mathbf{0}}\right)$}

Kapasitas dasar ditentukan berdasarkan jenis jalan, untuk jenis jalan 2 lajur tak bermedian kapasitas dasarnya adalah 2,900 smp/jam.

\section{Faktor Penyesuaian untuk Kapasitas}

1. Faktor penyesuaian lebar jalan $\left(\mathrm{FC}_{\mathrm{W}}\right)$

Untuk jalan dua lajur tak bermedian, total faktor penyesuaian adalah lebar jalan efektif $\left(\mathrm{W}_{\mathrm{e}}\right)$ 5,20 meter dengan faktor penyesuaian $\left(\mathrm{FC}_{\mathrm{W}}\right) \quad 0,72$ 
$\mathrm{Km} / \mathrm{Jam}$ didapat berdasarkan interpolasi linear.

2. Faktor penyesuaian pemisah arah $\left(\mathrm{FC}_{\mathrm{SP}}\right)$

Berdasarkan pedoman MKJI 1997

digunakan rumus sebagai berikut:

$\mathrm{SP}=\mathrm{Q}_{1} /\left(\mathrm{Q}_{1}+\mathrm{Q}_{2}\right) \times 100$

Dimana :

$\mathrm{Q}_{1}=$ Volume Lalu-Lintas 1

$\mathrm{Q}_{2}=$ Volume Lalu-Lintas 2

$\mathrm{Q}_{3}=$ Volume Lalu-Lintas Maksimum.

$\mathrm{SP}=404,3 /(404,3+352) \times 100$

Untuk tipe jalan (2/2 UD), faktor penyesuaian kapasitas pemisah arah didapat 53- 47 yang bernilai 0,97

3. Faktor penyesuaian hambatan samping $\left(\mathrm{FC}_{\mathrm{SF}}\right)$

Berdasarkan jenis jalan, dua lajur tak bermedian dengan hambatan samping tinggi, serta lebar bahu efektif rata-rata jalan 1,5 meter maka diperoleh faktor penyesuaian sebesar 0,95 .

4. Faktor penyesuaian ukuran kota $\left(\mathrm{FC}_{\mathrm{CS}}\right)$

Berdasarkan tabel 4.1, dari data yang didapat dari kantor Badan Pusat Statistik Kota Sorong diketahui jumlah penduduk kota sorong dalam angka 2016 mencapai 225,588 ribu jiwa $(<1$ juta penduduk ), digunakan faktor penyesuaian sebesar 0,86

Perhitungan Kapasitas Ruas Jalan

$\mathrm{C}=\mathrm{C}_{0} \times \mathrm{FC}_{\mathrm{W}} \times \mathrm{FC}_{\mathrm{SP}} \times \mathrm{FC}_{\mathrm{SF}} \times \mathrm{FC}_{\mathrm{CS}}$ (Smp/Jam).

$\mathrm{C}=2,900 \times 0,72 \times 0,97 \times 0,95 \times 0,86$

$=1654 \mathrm{Smp} / \mathrm{Jam}$.

Maka kapasitas total adalah sebesar $1654 \mathrm{Smp} / \mathrm{Jam}$.

\section{Analisa Derajat Kejenuhan (DS)}

Derajat kejanuhan adalah perbandingan dari volume (nilai arus) lalu-lintas terhadap kapasitasnya, derajat kejenuhan dapat dihitung :
Berikut ini adalah hasil perhitungan derajat kejenuhan pada hari rabu dapat dilihat pada tabel 7 dibawah ini.

Tabel 7. Analisa Derajat Kejenuhan pada Hari Rabu

\begin{tabular}{|c|c|c|c|}
\hline Walso (laas) & $\begin{array}{l}\text { Ans Labohintas } \\
\qquad 901 \\
\text { isaplani }\end{array}$ & $\begin{array}{l}\text { Kapuitas } \\
\text { (C) } \\
\text { Saplani }\end{array}$ & $\begin{array}{c}\text { Derajat Kejomban } \\
\text { (DS) }\end{array}$ \\
\hline 09:36-10 10 Wit & 7863 & 1654 & $6+6$ \\
\hline 11: $36-12$ :36 Wit & +956 & 1654 & 0.30 \\
\hline $17: 90-18.06$ Wit & 3217 & 164 & 6.21 \\
\hline
\end{tabular}

Dapat dilihat pada tabeldiatas nilai derajat kejenuhan pada hari rabu pukul 09:30-10:30 didapat nilai 0,46 sedangkan pada pukul 11:30-12:30 didapat nilai derajat kejenuhan 0,30 dan pada pukul 17:00-18:00 didapat nilai derajat kejenuhan 0,21, berdasarkan pedoman MKJI 1997 batas nilai derajat kejenuhan untuk jalan perkotaan adalah 0,75 bila nilai diatas melewati batas yang telah diberlakukan di MKJI 1997, itu berarti jalan tersebut mempunyai masalah/jenuh.

\section{Kecepatan Kendaraan Ringan (LV)}

Untuk mendapatkan nilai kecepatan kendaraan ringan berdasarkan fungsi DS sesuai yang disarankan MKJI 1997 digunakan grafik gambar 4 untuk jalan 2/2 UD. Dengan nilai $\mathrm{FV}_{\mathrm{LV}}=32,61$ $\mathrm{Km} / \mathrm{jam}$ digunakan DS tebesar 0,46. Didapat nilai kecepatan kendaraan ringan $\mathrm{V}_{\mathrm{LV}}=28 \mathrm{~km} / \mathrm{jam}$.

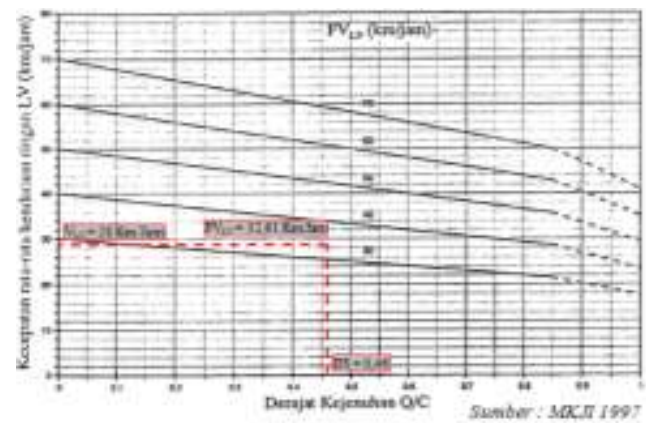

Gambar 3. Grafik Kecepatan Arus Bebas Kendaraan Ringan

\section{Waktu Tempuh}

Hubungan antara kecepatan (V) dan waktu tempuh (TT), dinyatakan dalam 
hasil perhitungan didapat $\mathrm{V}_{\mathrm{LV}}=28$ $\mathrm{Km} / \mathrm{Jam}$.

Dari data lapangan didapat $\mathrm{L}=0,2 \mathrm{Km}$.

$\mathrm{TT}=0,2 \mathrm{Km} / 28=0,007417 \mathrm{x}$ 3600 (MKJI)

$$
=25,71 \text { detik }
$$

\section{Analisa Tingkat Pelayanan Jalan}

Berdasarkan hasil analisis diatas, maka dapat ditentukan tingkat kinerja jalan A.M Sangaji Gonof Km.12 sesuai dengan ketetapan MKJI,1997. Tingkat pelayanan jalan dapat dilihat pada tabel-tabel dibawah ini. Berikut ini adalah klasifikasi tingkat pelayanan jalan berdasarkan nilai derajat kejenuhan pada hari rabu dapat dilihat pada tabel 8 dibawah ini.

Tabel 8. Klasifikasi Tingkat Pelayanan Jalan Pada Hari Rabu

\begin{tabular}{|c|c|c|c|}
\hline Waktu (Jam) & $\begin{array}{c}\text { Derajat Kegenuhas } \\
\text { (DS) }\end{array}$ & $\begin{array}{l}\text { Kriteria } \\
N(C)\end{array}$ & $\begin{array}{c}\text { Tingkat Pelayanan } \\
\text { Jalan (Los) }\end{array}$ \\
\hline 09:30-10:30 Wit & 0.46 & $0.45-0.74$ & C \\
\hline 11:30-12:30 wit & 0.30 & $021 \cdot 11.44$ & B \\
\hline $17: 00-18: 00$ Wit & 0.21 & $021-0.44$ & B \\
\hline
\end{tabular}

Dari tabel diatas didapat tingkat pelayanan jalan (Level of Service), pada pukul 09:30 - 10:30 adalah C yaitu kecepatan arus masih stabil, kecepatan dan pergerakan lebih ditentukan oleh volume yang tinggi, sedangkan pada pukul 11:30 - 12:30 adalah B yaitu keadaan arus stabil, kecepatan perjalanan mulai dipengaruhi oleh keadaan lalu-lintas, dalam batas dimana pengemudi masih mendapatkan kebebasan yang cukup dalam memilih kecepatannya, dan pada pukul 17:00 18:00 adalah B yaitu keadaan arus stabil, kecepatan perjalanan mulai dipengaruhi oleh keadaan lalu-lintas, dalam batas dimana pengemudi masih mendapatkan kebebasan yang cukup dalam memilih kecepatannya.

\section{Analisa Skenario Hambatan Samping}

Untuk mengetahui hubungan antara kecepatan dengan faktor hambatan samping yang terdapat pada ruas jalan A.M Sangaji Gonof Km12 saat jam puncak dengan menggunakan grafik pada MKJI,1997 dibuat skenario sebagai berikut:

1. Kondisi tanpa pejalan kaki/penyeberang jalan (No. PK) $\rightarrow$ (Skenario 1).

2. Kondisi tanpa kendaraan parkir/berhenti (No. KP) $\rightarrow$ (Skenario 2).

3. Kondisi tanpa pejalan kaki/penyeberang jalan dan kendaraan parkir/berhenti (No. $\mathrm{PK}+\mathrm{KP}) \rightarrow($ Skenario 3$)$.

Skenario ini dibuat untuk mengetahui keadaan suatu ruas jalan apabila jalan tersebut tidak dipengaruhi oleh suatu hambatan, dengan cara menghilangkan satu atau dua hambatan samping yang ada. Penghilangan hambatan samping akan berpengaruh pada faktor penyesuaian yang nantinya akan dihitung kapasitas ruas jalan, kecepatan arus bebas, derajat kejenuhan dan tingkat pelayanan jalan.
Kondisi
Tanpa
Kaki/Penyeberang (No.PK)
Pejalan

Dalam menganalisa kondisi ruas jalan tanpa pejalan kaki/penyeberang jalan, akan dihilangkan nilai kejadian hamabatan samping, digunakan nilai tertinggi untuk kebutuhan analisa tersebut.

Analisa Hambatan Samping.

Berikut ini digunakan jumlah kejadian hambatan samping tertinggi pada hari rabu, untuk selengkapnya dapat dilihat pada lampiran.

Tabel 9. Skenario Tanpa Pejalan Kaki/ Penyeberang Hari Rabu

\begin{tabular}{|c|c|c|c|c|c|c|c|c|c|c|}
\hline \multicolumn{11}{|c|}{ 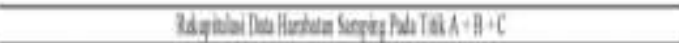 } \\
\hline \multirow{3}{*}{ Kinclas! } & \multirow{2}{*}{\multicolumn{4}{|c|}{ flatine xuepay }} & \multicolumn{4}{|c|}{ औbi } & \multirow{3}{*}{ - Tad } & \multirow{3}{*}{$\begin{array}{l}\text { Sola } \\
\text { linitus } \\
\text { Sage }\end{array}$} \\
\hline & & & & & \multirow{2}{*}{$\frac{(\mathrm{A})}{03}$} & \multirow{2}{*}{$\frac{(B)}{1}$} & \multirow{2}{*}{$\frac{06}{09}$} & \multirow{2}{*}{$\frac{\text { [N] }}{\Delta 4}$} & & \\
\hline & $(15)$ & $(9)$ & SW & (12) & & & & & & \\
\hline (14250 & il & 19 & 15 & 9 & 9 & 16 & फ3 & 36 & 515 & 1 \\
\hline 113409 & i) & 7) & B & 1 & $\overline{0}$ & 8 & 53 & 2 & 123 & I \\
\hline $1204 \times 0$ & i & 5 & EI & 4 & 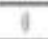 & 2 & St & 16 & Ho & I \\
\hline
\end{tabular}


Dari hasil skenario diatas yang sebelumnya pada pukul 09:30 - 10:30 didapat total bobot 333 dengan kelas hambatan samping sedang/medium. Dengan skenario 1 didapat total bobot 2505,5 dengan kelas hambatan samping rendah/low. Kemudian pada pukul 11:30 - 12:30 didapat total bobot yang sebelumnya 225,3 dengan kelas hambatan samping rendah/low. Dengan skenario didapat total bobot 174,3 dengan kelas hambatan samping rendah/low dan pada pukul 17:00 18:00 sebelumnya didapat total bobot 190 dengan kelas hambatan samping rendah/Low. Dengan skenario didapat total bobot 146 dengan kelas hamabatan samping rendah/Low

Perhitungan Kecepatan Arus Bebas (FV)

$\mathrm{FFV}=\left(\mathrm{FV}_{\mathrm{O}}+\mathrm{FV}_{\mathrm{W}}\right) \times \mathrm{FFV}_{\mathrm{SF}} \times \mathrm{FFV}_{\mathrm{CS}}$ $(\mathrm{Km} / \mathrm{Jam})$

a. Untuk jenis kendaraan ringan (LV)

$\mathrm{FV}=(44+-6,25) \times 0,99 \times 0,90$

$$
=33,63 \mathrm{Km} / \mathrm{Jam}
$$

b. Untuk jenis kendaraan berat (HV)

$$
\begin{aligned}
\mathrm{FV} & =(40+-6,25) \times 0,99 \times 0,90 \\
& =30,17 \mathrm{Km} / \mathrm{Jam}
\end{aligned}
$$

c. Untuk jenis sepeda motor (MC)

$$
\begin{aligned}
\mathrm{FV} & =(40+-6,25) \times 0,99 \times 0,90 \\
& =30,17 \mathrm{Km} / \mathrm{Jam}
\end{aligned}
$$

Perhitungan Kapasitas Ruas Jalan (C)

$\mathrm{C}=\mathrm{C}_{0} \times \mathrm{FC}_{\mathrm{W}} \times \mathrm{FC}_{\mathrm{SP}} \times \mathrm{FC}_{\mathrm{SF}} \times \mathrm{FC}_{\mathrm{CS}}$ (Smp/Jam).

$\mathrm{C}=2,900 \times 0,72 \times 0,97 \times 0,97 \times$ 0,86

$$
=1689 \mathrm{Smp} / \mathrm{Jam} \text {. }
$$

\begin{tabular}{|c|c|c|c|}
\hline Waktn (Jam) & $\begin{array}{c}\text { (Q) } \\
\text { (Smą) Jam) }\end{array}$ & $\begin{array}{c}\text { (C) } \\
\text { (Senpiast) }\end{array}$ & $\begin{array}{c}\text { Dersjat } \\
\text { Kejennatas (DS) }\end{array}$ \\
\hline $09-30-10-30 \mathrm{Wit}$ & 756,3 & 1689 & 0.44 \\
\hline $1130-12.30 \mathrm{Wit}$ & 495,6 & 1689 & 0.29 \\
\hline $17.00-18.00$ Wit & 341,7 & 1689 & 0.20 \\
\hline
\end{tabular}

Maka kapasitas total adalah sebesar 1689 Smp/Jam.

Analisa Derajat Kejenuhan (DS)

Tabel 10. DS Tanpa Pejalan Kaki/ Penyeberang Hari Rabu
Kecepatan Kendaraan Ringan (LV)

Dengan nilai $\mathrm{FV}_{\mathrm{LV}}=33,63 \mathrm{Km} / \mathrm{jam}$ digunakan DS tebesar 0,44. Didapat nilai kecepatan kendaraan ringan $\mathrm{V}_{\mathrm{LV}}=$ $29 \mathrm{~km} / \mathrm{jam}$.

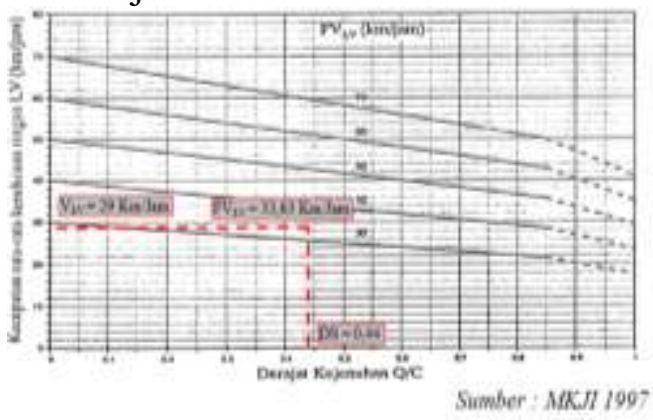

Gambar 4. Grafik Kecepatan Arus Bebas Kendaraan Ringan

Kecepatan Tempuh.

Hubungan antara kecepatan (V) dan waktu tempuh (TT), dinyatakan dalam persamaan yang mengacu pada persamaan 6 .

Dari hasil perhitungan didapat $\mathrm{V}_{\mathrm{LV}}=$ $29 \mathrm{Km} / \mathrm{Jam}$.

Dari data lapangan didapat $\mathrm{L}=0,2 \mathrm{Km}$. $\mathrm{TT}=0,2 \mathrm{Km} / 29$

$$
\begin{aligned}
& =0,006897 \times 3600(\mathrm{MKJ}) \\
& =24,82 \text { detik. }
\end{aligned}
$$

\begin{tabular}{|c|c|c|c|}
\hline Waistu (Im) & $\begin{array}{c}\text { Deriya } \\
\text { Kgicruban } \\
\text { (DS) }\end{array}$ & $\begin{array}{l}\text { Kriteria } \\
\text { (WC) }\end{array}$ & $\begin{array}{c}\text { Tinglest } \\
\text { Pelaymin haln } \\
\text { (Los) }\end{array}$ \\
\hline $09-30-10-30 \mathrm{~W}$ it & 0.44 & $0.21-0.44$ & B \\
\hline II:30-12:30 Wit & 029 & $0.21 \cdot 0.44$ & B \\
\hline $17.00-18.00$ Wit & 020 & $0.00-0.20$ & A \\
\hline
\end{tabular}

Analisa Tingkat Pelayanan Jalan (LOS) Berikut ini adalah klasifikasi tingkat pelayanan jalan berdasarkan nilai derajat kejenuhan pada hari rabu dapat dilihat pada tabel 11 dibawah ini.

Tabel 11. LOS Tanpa Pejalan Kaki/ Penyeberang Hari Rabu

\section{Kondisi Tanpa Kendaraan Parkir/Berhenti (No. KP)}

Dalam menganalisa kondisi ruas jalan tanpa kendaraan berhenti/parkir, akan dihilangkan nilai kejadian hamabatan samping, digunakan nilai tertinggi untuk kebutuhan analisa tersebut. 
Analisa Hambatan Samping

Berikut ini digunakan jumlah kejadian hambatan samping tertinggi pada hari rabu, untuk selengkapnya dapat dilihat pada lampiran.

Tabel 12. Skenario Tanpa Kendaraan Berhenti /Parkir Hari Rabu

\begin{tabular}{|c|c|c|c|c|c|c|c|c|c|c|}
\hline \multirow{4}{*}{ (lai) } & \multicolumn{8}{|c|}{ 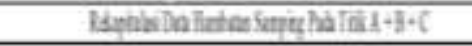 } & \multirow{4}{*}{ In } & \multirow{4}{*}{ 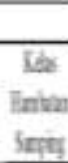 } \\
\hline & \multirow{2}{*}{\multicolumn{4}{|c|}{ Hintoriertip }} & \multicolumn{4}{|c|}{ bith } & & \\
\hline & & & & & A. & B & (W) & 쵼. & & \\
\hline & ( & B. & 政 & (2) & 15 & 1 & it & 44 & & \\
\hline 13: & $\sqrt{15}$ & 1 & BI & 9 & c5 & 1 & 可! & if & IS & 1 \\
\hline 13) & II & 1 & Bi & 5 & \$1 & 1 & $f 3$ & 2 & 193 & 1 \\
\hline in & 青 & 1 & E & 4 & H & 8 & St & If & III & 1 \\
\hline
\end{tabular}

Dari hasil skenario diatas yang sebelumnya pada pukul 09:30 - 10:30 didapat total bobot 333 dengan kelas hambatan samping sedang/medium. Dengan skenario 2 didapat total bobot 182 dengan kelas hambatan samping rendah/low. Kemudian pada pukul 11:30 - 12:30 didapat total bobot yang sebelumnya 225,3 dengan kelas hambatan samping rendah/low. Dengan skenario didapat total bobot 150,3 dengan kelas hambatan samping rendah/low dan pada pukul 17:00 18:00 sebelumnya didapat total bobot 190 dengan kelas hambatan samping rendah/Low. Dengan skenario didapat total bobot 138 dengan kelas hamabatan samping rendah/Low Perhitungan Kecepatan Arus Bebas (FV)

$\mathrm{FFV}=\left(\mathrm{FV}_{\mathrm{O}}+\mathrm{FV}_{\mathrm{W}}\right) \times \mathrm{FFV}_{\mathrm{SF}} \mathrm{x} \mathrm{FFV}_{\mathrm{CS}}$ $(\mathrm{Km} / \mathrm{Jam})$

a. Untuk jenis kendaraan ringan(LV)

$\mathrm{FV}=(44+-6,25) \times 0,99 \times 0,90$

$$
=33,63 \mathrm{Km} / \mathrm{Jam}
$$

b. Untuk jenis kendaraan berat (HV)

$$
\mathrm{FV}=(40+-6,25) \times 0,99 \times 0,90
$$$$
=30,17 \mathrm{Km} / \mathrm{Jam}
$$

c. Untuk jenis sepeda motor (MC)

$$
\mathrm{FV}=(40+-6,25) \times 0,99 \times 0,90
$$

$$
=30,17 \mathrm{Km} / \mathrm{Jam}
$$

Perhitungan Kapasitas Ruas Jalan (C)
$\mathrm{C}=\mathrm{C}_{0} \times \mathrm{FC}_{\mathrm{W}} \times \mathrm{FC}_{\mathrm{SP}} \times \mathrm{FC}_{\mathrm{SF}} \times \mathrm{FC}_{\mathrm{CS}}$ (Smp/Jam).

$\mathrm{C}=2,900 \times 0,72 \times 0,97 \times 0,97 \times 0,86$ $=1689 \mathrm{Smp} / \mathrm{Jam}$.

Maka kapasitas total adalah sebesar 1689 Smp/Jam.

Analisa Derajat Kejenuhan (DS)

Berikut ini adalah hasil perhitungan

\begin{tabular}{|c|c|c|c|}
\hline Waktu (Jam) & $\begin{array}{c}\text { (Q) } \\
\text { (Smp Jam) }\end{array}$ & $\begin{array}{c}\text { (C) } \\
\text { (Smp Jam) }\end{array}$ & $\begin{array}{c}\text { Derajal } \\
\text { Kejeuthan (DS) }\end{array}$ \\
\hline $0930-11-30$ Wit & 756.3 & 1689 & 0.44 \\
\hline $1130 \cdot 12: 30 \mathrm{Wt}$ & 495.6 & 1689 & 0.29 \\
\hline 17:00-18:00 Wit & 341.7 & 1689 & 0.20 \\
\hline
\end{tabular}
derajat kejenuhan .

Tabel 13. DS Tanpa Kendaraan

Berhenti /Parkir Hari Rabu

Kecepatan Kendaraan Ringan (LV)

Dengan nilai $\mathrm{FV}_{\mathrm{LV}}=33,63 \mathrm{Km} / \mathrm{jam}$ digunakan DS tebesar 0,44. Didapat nilai $V_{L V}=29 \mathrm{~km} / \mathrm{jam}$.

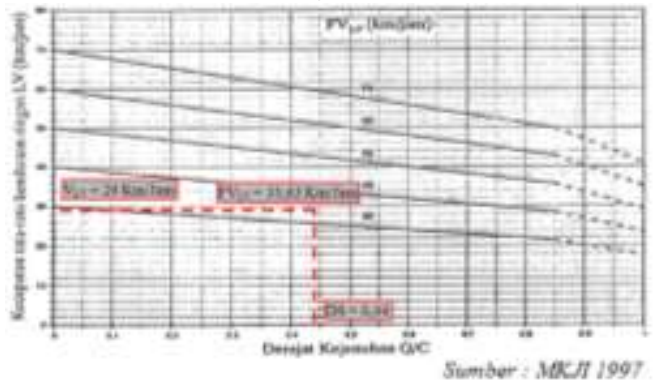

Gambar 5. Grafik Kecepatan Arus

Bebas Kendaraan Ringan

Kecepatan Tempuh.

Hubungan antara kecepatan (V) dan waktu tempuh (TT), dinyatakan dalam persamaan yang mengacu pada persamaan 6 .

Dari hasil perhitungan didapat $\mathrm{V}_{\mathrm{LV}}=$ $39 \mathrm{Km} / \mathrm{Jam}$.

Dari data lapangan didapat $\mathrm{L}=0,2 \mathrm{Km}$. $\mathrm{TT}=0,2 \mathrm{Km} / 29=0,006897 \mathrm{x}$ 3600(MKJI) $=24,82$ detik

Analisa Tingkat Pelayanan Jalan (LOS) Berikut ini adalah klasifikasi tingkat pelayanan jalan berdasarkan nilai derajat kejenuhan pada hari rabu dapat dilihat pada tabel 14 dibawah ini. 
Tabel 14. LOS Tanpa Kendaraan Berhenti /Parkir Hari Rabu

\begin{tabular}{|c|c|c|c|}
\hline Waktu (Jam) & $\begin{array}{l}\text { Derajat } \\
\text { Kejenuhan } \\
\text { (DS) }\end{array}$ & $\begin{array}{c}\text { Kriteria } \\
(M C)\end{array}$ & $\begin{array}{c}\text { Tingkat } \\
\text { Pelayanan Jalan } \\
\text { (Los) }\end{array}$ \\
\hline $09-30-10-30$ Wit & 0.44 & $0.2 \mathrm{I}-0.4 \mathrm{H}$ & B \\
\hline $11: 30-12: 30 \mathrm{Wit}$ & 029 & $0.21-0.44$ & B \\
\hline $17.00-18: 00$ Wit & 0.20 & $0.00-0.20$ & A \\
\hline
\end{tabular}

$\begin{array}{lccr}\text { Kondisi } & \text { Tanpa } & \text { Pejalan } \\ \text { Kaki/Penyeberang } & \text { Jalan } & \text { dan } \\ \text { Kendaraan } & \text { Parkir/Berhenti } & \text { (No. } \\ \text { PK+KP) } & & \end{array}$

Dalam menganalisa kondisi ruas jalan tanpa pejalan kaki/penyeberang jalan dan kendaraan berhenti/parkir. Akan dihilangkan nilai kejadian hamabatan samping, digunakan nilai tertinggi untuk kebutuhan analisa tersebut.

Analisa Hambatan Samping

Berikut ini digunakan jumlah kejadian hambatan samping tertinggi pada hari rabu, untuk selengkapnya dapat dilihat pada lampiran.

Tabel 15. Skenario 3 (No PK+KP) Hari Rabu

\begin{tabular}{|c|c|c|c|c|c|c|c|c|c|c|}
\hline \multicolumn{11}{|c|}{ 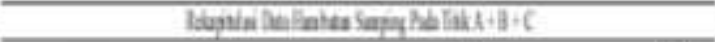 } \\
\hline \multirow{3}{*}{$\operatorname{Vial}(\mathbf{n})$} & \multirow{2}{*}{\multicolumn{4}{|c|}{ Enitus Sajp }} & \multicolumn{4}{|c|}{ My } & \multirow{3}{*}{$\begin{array}{l}|l| d \mid \\
\text { Sitet }\end{array}$} & \multirow{3}{*}{$\begin{array}{l}\text { Kds } \\
\text { liation } \\
\text { Sangs }\end{array}$} \\
\hline & & & & & $\mathrm{N}$ & (D) & SV & (1) & & \\
\hline & $\mathrm{AN}$ & (D) & (M0 & (10) & 15 & 1 & is & 01 & & \\
\hline 634t3 & 1 & 1 & (8) & 9 & 1 & 1 & 69 & 36 & Fis & $\pi$ \\
\hline IIxa! & $i$ & 1 & B & 3 & $i$ & $i$ & A3 & 2 & \$63 & 7 \\
\hline Barin & 1 & 1 & ES & 1 & 1 & 1 & 84 & 16 & 臬 & II \\
\hline
\end{tabular}

Dari hasil skenario diatas yang sebelumnya pada pukul 09:30 - 10:30 didapat total bobot 333 dengan kelas hambatan samping sedang/medium. Dengan skenario 3 didapat total bobot 99,5 dengan kelas hambatan samping sangat rendah/very low. Kemudian pada pukul 11:30 - 12:30 didapat total bobot yang sebelumnya 225,3 dengan kelas hambatan samping rendah/low. Dengan skenario didapat total bobot 99,3 dengan kelas hambatan samping sangat rendah/very low dan pada pukul 17:00 - 18:00 sebelumnya didapat total bobot 190 dengan kelas hambatan samping rendah/Low. Dengan skenario didapat total bobot 94 dengan kelas hambatan samping sangat rendah.

Perhitungan Kecepatan Arus Bebas (FV)

$$
\mathrm{FFV}=\left(\mathrm{FV}_{\mathrm{O}}+\mathrm{FV}_{\mathrm{W}}\right) \mathrm{x} \mathrm{FFV}_{\mathrm{SF}} \mathrm{x}
$$

$$
\mathrm{FFV}_{\mathrm{CS}}(\mathrm{Km} / \mathrm{Jam})
$$

a. Untuk jenis kendaraan ringan (LV)

$\mathrm{FV}=(44+-6,25) \times 1,01 \times 0,90$

$=34,32 \mathrm{Km} / \mathrm{Jam}$

b. Untuk jenis kendaraan berat (HV)

$\mathrm{FV}=(40+-6,25) \times 1,01 \times 0,90$

$=30,67 \mathrm{Km} / \mathrm{Jam}$

c. Untuk jenis sepeda motor (MC)

$\mathrm{FV}=(40+-6,25) \times 1,01 \times 0,90$

$=30,67 \mathrm{Km} / \mathrm{Jam}$

Perhitungan Kapasitas Ruas Jalan (C)

$\mathrm{C}=\mathrm{C}_{0} \times \mathrm{FC}_{\mathrm{W}} \times \mathrm{FC}_{\mathrm{SP}} \times \mathrm{FC}_{\mathrm{SF}} \times \mathrm{FC}_{\mathrm{CS}}$ (Smp/Jam).

$$
\begin{aligned}
\mathrm{C} & =2,900 \times 0,72 \times 0,97 \times 0,99 \times 0,86 \\
& =1724 \mathrm{Smp} / \mathrm{Jam} .
\end{aligned}
$$

Maka kapasitas total adalah sebesar 1724 Smp/Jam.

Analisa Derajat Kejenuhan (DS)

\begin{tabular}{|c|c|c|c|}
\hline Walto (lan) & $\begin{array}{c}(Q) \\
(\text { Smp } / m)\end{array}$ & $\begin{array}{c}\text { (C) } \\
\text { (Sop lata) }\end{array}$ & $\begin{array}{c}\text { Durajat } \\
\text { Kejemihan (D8) }\end{array}$ \\
\hline $09-30-10-30$ Wit & 7863 & 1724 & e.43 \\
\hline $11-30-12: 20 W_{i t}$ & 495.6 & 1724 & 628 \\
\hline $1700-1500$ Wil & 31.7 & 1724 & e.19 \\
\hline
\end{tabular}

Tabel 16. (DS) Tanpa Pejalan Kaki

/Penyeberang Jalan dan Kendaraan Parkir/Berhenti Hari Rabu

Kecepatan Kendaraan Ringan (LV)

Dengan nilai $\mathrm{FV}_{\mathrm{LV}}=34,32 \mathrm{Km} / \mathrm{jam}$ digunakan DS tebesar 0,43. Didapat nilai kecepatan kendaraan ringan $\mathrm{V}_{\mathrm{LV}}=$ $30 \mathrm{~km} / \mathrm{jam}$.

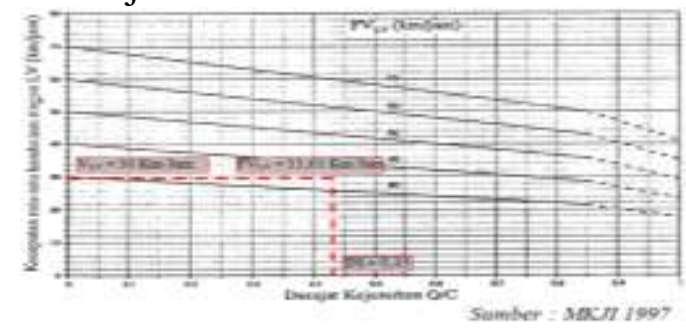

Gambar 6. Grafik Kecepatan Arus Bebas Kendaraan Ringan 
Kecepatan Tempuh.

Hubungan antara kecepatan (V) dan waktu tempuh (TT), dinyatakan dalam persamaan yang mengacu pada persamaan 6 .

Dari hasil perhitungan didapat $\mathrm{V}_{\mathrm{LV}}=$ $30 \mathrm{Km} / \mathrm{Jam}$.

Dari data lapangan didapat $\mathrm{L}=0,2 \mathrm{Km}$.

$\mathrm{TT}=0,2 \mathrm{Km} / 30=0,006667 \mathrm{x}$ 3600(MKJI)

$$
=24,00 \text { detik }
$$

Analisa Tingkat Pelayanan Jalan (LOS) Berikut ini adalah klasifikasi tingkat pelayanan jalan berdasarkan nilai derajat kejenuhan pada hari rabu dapat dilihat pada tabel 17 dibawah ini.

Tabel 17. (LOS) Tanpa Pejalan Kaki

/Penyeberang Jalan dan Kendaraan

Berhenti/Parkir Hari Rabu

\begin{tabular}{|c|c|c|c|}
\hline Wakte (Jaa) & $\begin{array}{c}\text { Derajat } \\
\text { Kejenuhas } \\
\text { (DS) }\end{array}$ & $\begin{array}{c}\text { Kriteria } \\
(V C)\end{array}$ & $\begin{array}{c}\text { Tangkat } \\
\text { Pelayanan Jalan } \\
\text { (Los) }\end{array}$ \\
\hline 09:30-10:30 Wit & 0.43 & $0.21 \cdot 0.4$ & C \\
\hline $11: 30-12,30 \mathrm{Wif}$ & 0.28 & $0.21 \cdot 0.4$ & B \\
\hline $17: 00-18: 00$ Wit & 0.19 & $0.00 \cdot 0.20$ & A \\
\hline
\end{tabular}

\section{KESIMPULAN}

Berdasarkan hasil pengolahan data dapat diambil kesimpulan :

1. Berdasarkan analisa jalan perkotaan menggunakan pedoman MKJI 1997, kondisi ruas jalan A.M Sangaji Gonof Km.12 akibat pengaruh kelas hambatan samping sedang/medium didapat faktor penyesuaian sebesar 0,95 sehingga di dapat kapasitas $1654 \mathrm{Smp} / \mathrm{Jam}$ dengan nilai derajat kejenuhan 0,46. Kemudian pada skenario 1 dan 2 akibat pengaruh kelas hambatan samping rendah/low didapat faktor penyesuaian sebesar 0,97 sehingga didapat kapasitas $1689 \mathrm{Smp} / J a m$ dengan nilai derajat kejenuhan 0,44 . Lalu pada skenario 3 akibat pengaruh kelas hambatan samping sangat rendah/very low didapat faktor penyesuaian sebesar
0,99 sehingga didapat kapasitas 1724 Smp/Jam dengan nilai derajat kejenuhan 0,43 dapat disimpulkan bahwa peningkatan nilai penyesuaian hambatan samping dapat meningkatkan kapasitas ruas jalan dan dapat menurunkan nilai derajat kejenuhan.

2. Berdasarkan rumusan masalah poin dua, kinerja ruas jalan A.M. Sangaji Gonof Km.12 Kota Sorong pada kondisi existing/saat ini didapat jumlah bobot hambatan samping sebesar 333 dengan kelas hambatan samping sedang/medium, didapat nilai kecepatan arus bebas kendaraan ringan (FV) sebesar 32,61 Km/Jam, kapasitas total adalah $1654 \mathrm{Smp} / \mathrm{Jam}$, nilai derajat kejenuhan $0,46, \quad \mathrm{~V}_{\mathrm{LV}}=28,00$ $\mathrm{Km} / \mathrm{Jam}$, nilai $\mathrm{TT}=25,71$ detik dan nilai tingkat pelayanan jalan $\mathrm{C}$ sedangkan kinerja ruas jalan menggunakan skenario 3 didapat jumlah bobot hambatan samping sebesar 99,5 dengan kelas hambatan samping sangat rendah/ very low, didapat nilai kecepatan arus bebas kendaraan ringan (FV) sebesar $34,32 \mathrm{Km} / \mathrm{Jam}$, kapasitas total adalah $1724 \mathrm{Smp} / \mathrm{Jam}$, nilai derajat kejenuhan $0,43, \mathrm{~V}_{\mathrm{LV}}=30 \mathrm{Km} / \mathrm{Jam}$, nilai $\mathrm{TT}=24,00$ detik dan nilai tingkat pelayanan jalan $\mathrm{C}$ dari pembahasan diatas dapat ditarik kesimpulan dapat dilihat penurunan jumlah bobot hambatan samping sebesar 29\% menggunakan skenario 3 yang awal nyaa kelas hambatan samping tinggi menjadi rendah, kemudian peningkatan kapasitas sebesar $1,14 \%$ yang sebelumnya 1654 meningkat menjadi 1724, kemudian penurunan nilai derajat kejenuhan sebesar 0,93 \% yang sebelumnya $0,46 \quad$ kemudian menurun menjadi 0,43 . 
3. Didapat jumlah bobot hambatan samping tertinggi pada hari rabu pukul 09:30 - 10:30 sebesar 333, kemudian didapat kapasitas ruas jalan total sebesar $1654 \mathrm{Smp} / \mathrm{Jam}$, dan nilai derajat kejenuhannya sebesar 0,46 berdasarkan nilai derjat kejenuhan diatas didapat tingkat pelayanan jalan $\mathrm{C}$ yaitu kecepatan arus masih stabil, kecepatan dan pergerakan lebih ditentukan oleh volume tinggi.

\section{DAFTAR PUSTAKA}

Alamsyah, Alik Ansyori, (2008). Rekayasa Lalu Lintas Edisi Revisi, UPT Penerbit Universitas Muhammadiyah, Malang.

Caesar, D. (2014). Analisis Kinerja Jalan Akibat Pengaruh Hambatan Samping di Jalan Diponegoro Kota Banda Aceh. Skripsi. Banda Aceh : Universitas Syiah Kuala.

Dapartemen Pekerjaan Umum (1997). Manual Kapasitas Jalan Indonesia, Direktorat Jenderal Bina Marga, Jakarta.

I Made, T., \& I Ketut, S. Pengaruh Hambatan Samping Terhadap Kapasitas Ruas Jalan Cokroaminoto Denpasar. Jurnal. Bali : Politeknik Negeri Bali.

Panahatan, M. (2005). Analisa Hambatan Samping Sebagai Akibat Penggunaan Lahan Sekitarnya Terhadap Kinerja Jalan Juanda Di Kota Bekasi. Tesis. Semarang : Universitas Diponegoro.

Pristianto, H., Amri, I., \& Rusdi, A. (2018). Pedoman Penulisan Tugas Akhir Fakultas Teknik Universitas Muhammadiyah Sorong.

Septyanto, K. (2015). Analisis Hambatan Samping Akibat Perdagangan Modern Jalan Brigjen Katamso Bandar Lampung. Jurnal.
Lampung : Universitas Muhammadiyah Metro.

Tamin Z, O.,(2000) Perencanaan dan Pemodelan Transportasi. Buku. Bandung : Penerbit Institut Teknologi Bandung. 